\title{
Symptomatic salicylate ototoxicity: a useful indicator of serum salicylate concentration?
}

\author{
James T Halla, Susan L Atchison, Joe G Hardin
}

\begin{abstract}
A three phase study was designed to define further the sensitivity and specificity of symptomatic salicylate ototoxicity (primarily tinnitus) for serum salicylate concentrations. In phase one 260 patients with osteoarthritis and 112 with rheumatoid arthritis, none taking salicylates, were interviewed about their ear symptoms. Their responses were not significantly different from those of 134 salicylate treated patients with rheumatoid arthritis previously reported. In the second phase 56 patients who were taking salicylates, and who volunteered the complaint of tinnitus, had serum salicylate concentrations measured while symptomatic, and 30 (54\%) had concentrations less than $1.3 \mathrm{mmol} / 1$. Few tolerated an upward salicylate dose adjustment. For phase three, 94 patients were found to have a salicylate concentration above $2.2 \mathrm{mmol} / \mathrm{l}$ on one or more occasion, and these subjects were interviewed. Fifty two patients (55\%) had no tinnitus, and tinnitus correlated with the blood salicylate concentration in only 28 (30\%). Audiological evaluation of most of the symptomatic patients was carried out, and results were abnormal in the majority, even in those patients not reporting tinnitus. Symptomatic salicylate ototoxicity is too nonspecific and too insensitive to be a useful indicator of serum salicylate concentration.
\end{abstract}

Tinnitus and subjective hearing loss, the major symptoms of salicylate ototoxicity, are generally thought to become apparent with increasing salicylate dosage and serum salicylate concentration. ${ }^{12}$ As salicylate dosages required to produce a non-toxic therapeutic serum concentration (generally regarded as $1 \cdot 1-2 \cdot 2 \mathrm{mmol} / \mathrm{l}$ ) are highly variable, clinical monitoring is often desirable. ${ }^{1-5}$ Although ototoxicity has been used for this purpose, we previously reported that tinnitus and subjective hearing loss are too nonspecific to be a reliable clinical tool for adjusting salicylate treatment. ${ }^{6}$ Patients with rheumatoid arthritis receiving salicylates had no more symptoms of ototoxicity than did a healthy control group not taking the drug, and in the patients with rheumatoid arthritis symptoms often occurred with serum salicylate concentrations less than $1.4 \mathrm{mmol} / \mathrm{l}$.

To define further the sensitivity and specificity of tinnitus and subjective hearing loss for therapeutic or toxic serum salicylate concentrations we interviewed two additional control groups who were not receiving salicylates, evaluated serum salicylate concentrations in $\mathbf{5 6}$ consecutive patients complaining of tinnitus, and interviewed all patients who were found to have a serum salicylate concentration equal to or greater than $2.2 \mathrm{mmol} / \mathrm{l}$ during a three year period.

\section{Subjects and methods}

Control subjects included 260 patients with osteoarthritis not receiving salicylates and 112 consecutive patients with rheumatoid arthritis who had not received salicylates for at least one and a half years. The first group of test subjects were 56 consecutive outpatients ( 51 with rheumatoid arthritis, five with osteoarthritis) receiving regular salicylate treatment who, unsolicited, volunteered the complaint of tinnitus. The second group of test subjects were 94 patients (88 with rheumatoid arthritis, three with osteoarthritis, three with other disease) who were found to have a serum salicylate concentration equal to or greater than $2.2 \mathrm{mmol} / \mathrm{l}$ on one or more occasions during a three year period.

All subjects were questioned about previous known ear disease, recent subjective hearing loss, and recent tinnitus. Tinnitus was defined as a persisting or recurrent unilateral or bilateral ringing, roaring, or buzzing sensation with each recurrence persisting for five minutes or longer.

All salicylate concentrations were measured in one laboratory by the ultraviolet spectrophotometric method of Keller. ${ }^{7}$

The audiological examination, including pure tone air conduction threshold, bone conduction threshold, and speech reception threshold, was performed by a certified audiologist under controlled conditions (sound booth with calibrated audiometer).

Statistical significance was calculated using the $\chi^{2}$ tests on percentages for the four group comparison and $t$ tests on paired samples.

\section{Results}

The prevalence of tinnitus and subjective hearing loss in 134 consecutive patients with rheumatoid arthritis taking salicylates regularly and 182 healthy subjects not using salicylates has previously been reported. ${ }^{6}$ Table 1 compares the results of that study with those for two additional control groups. There were no significant differences in either symptom among the four groups.

The 56 consecutive patients volunteering the complaint of tinnitus (table 2) fell into two groups: 30 with a serum salicylate concentration less than $1.3 \mathrm{mmol} / \mathrm{l}$ and 26 with a serum salicylate concentration greater than $1.4 \mathrm{mmol} / \mathrm{l}$.
Presented in part at the 52nd annual meeting of the American Rheumatism Association, Houston, Texas, May 1988. 
Table 1 Frequency of recent tinnitus and recent subjective hearing loss reported by 134 patients with rheumatoid arthritis and various control groups. Results are shown as number (percentage) of patients with the given symptom

\begin{tabular}{|c|c|c|c|c|}
\hline & $\begin{array}{l}\text { Patients with } \\
R A t \\
(n=134)\end{array}$ & $\begin{array}{l}\text { Control } 1 \\
(n=182)\end{array}$ & $\begin{array}{l}\text { Control } 2 \\
(n=112)\end{array}$ & $\begin{array}{l}\text { Control } 3 \\
(n=260)\end{array}$ \\
\hline $\begin{array}{l}\text { Tinnitus } \\
\text { Subjective hearing loss } \\
\text { Mean age (years) }\end{array}$ & $\begin{array}{l}46(34)^{*} \\
42(31) \mathrm{NS} \\
58 \cdot 3\end{array}$ & $\begin{array}{l}46(25)^{*} \\
51(28) \mathrm{NS} \\
34 \cdot 3\end{array}$ & $\begin{array}{l}24(21)^{*} \\
28(25) \mathrm{NS} \\
62 \cdot 6\end{array}$ & $\begin{array}{l}62(24)^{*} \\
69(26) \mathrm{NS} \\
69 \cdot 6\end{array}$ \\
\hline
\end{tabular}

*RA $v$ control 1, NS; RA $v$ control 2, $p=0.035$; RA $v$ control 3, $p=0.035$.

tPatients with RA, control 1 - previously reported ${ }^{6}$; control $2=$ patients with $R A$ with no salicylate treatment for at least one and a half years; control 3=patients with osteoarthritis receiving no salicylate treatment.

Table 2 Audiometric responses in 56 patients who volunteered tinnitus while receiving regular salicylate treatment. Results are given as number or number (percentage) of patients

\begin{tabular}{llc}
\hline & \multicolumn{2}{l}{ Salicylate concentration (mmolll) } \\
\cline { 2 - 3 } & $<l \cdot 3$ & $>1 \cdot 4$ \\
\hline Patients (number) & 30 & 26 \\
Mean age (years) & $56 \cdot 9$ & $54 \cdot 9$ \\
Disease duration (years) & $9 \cdot 1$ & $8 \cdot 9$ \\
Reported subjective hearing loss & $11(37)$ & $15(58)$ \\
Reported prior ear disease & $5(17)$ & $4(15)$ \\
Audiograms & 23 & 16 \\
Normal & 4 & 4 \\
Abnormal & $19(83)$ & $12(75)$ \\
Conductive hearing & 1 & 0 \\
Sensorineural hearing loss & 18 & 12 \\
$\quad$ High frequency (3000-8000 Hz) & $11(61)$ & $8(67)$ \\
\hline
\end{tabular}

Table 3 Classification of 94 patients with serum salicylate concentrations $>1.4 \mathrm{mmol} / \mathrm{l}$ according to the presence or absence of tinnitus. Number (percentage) of patients is given

\begin{tabular}{llll}
\hline & No tinnitus & $\begin{array}{l}\text { Tinnitus at salicylate } \\
\text { concentration } \\
>1 \cdot 4 \text { mmoll }\end{array}$ & $\begin{array}{l}\text { Tinnitus unrelated to } \\
\text { salicylate concentration } \\
>1.4 \\
\text { mmolll }\end{array}$ \\
\hline Number of patients & $52(55)$ & $28(30)$ & $14(15)$ \\
Mean age (years) & $58 \cdot 8$ & $57 \cdot 2$ & 63.9 \\
Mean disease duration (years) & 13.3 & $10 \cdot 6$ & $13 \cdot 1$ \\
Subjective hearing loss & $15(29)$ & $15(54)$ & $7(50)$ \\
Reported previous ear disease & $8(15)$ & $4(14)$ & $5(36)$ \\
\hline
\end{tabular}

Table 4 Results of audiometric responses in 54 patients with a serum salicylate concentration greater than $1.4 \mathrm{mmol} / \mathrm{l}$. Number of patients is shown

\begin{tabular}{lccccc}
\hline $\begin{array}{l}\text { Audiometric } \\
\text { response }\end{array}$ & Normal & $\begin{array}{l}\text { Mixed } \\
\text { hearing } \\
\text { loss }\end{array}$ & & \multicolumn{3}{c}{ Sensorineural hearing loss } \\
\cline { 5 - 7 } & & & Mild & Moderate & Severe \\
\hline All patients & 15 & 2 & 15 & 14 & 8 \\
Patients with tinnitus & 5 & 1 & 7 & 3 & 4 \\
Patients without tinnitus & 10 & 1 & 8 & 11 & 4 \\
Patients with subjective hearing loss & 3 & 1 & 3 & 6 & 4 \\
Patients reporting previous ear disease & 1 & 0 & 1 & 3 & 5 \\
Mean age (years) & $42 \cdot 5^{*}$ & $52 \cdot 5$ & $60.0^{*}$ & $66.4^{*}$ & 65.6 \\
Disease duration (years) & $6.9+$ & 8.0 & $13.3+$ & $13.9 \dagger$ & 11.8 \\
\hline
\end{tabular}

*Normal. $v$ mild sensorineural hearing loss, $\mathrm{p}=0.03$; normal $v$ moderate sensorineural hearing loss, $\mathrm{p}<0.02$.

tNormal $v$ mild and moderate sensorineural hearing loss, $p<0.001$.

In the latter group only 10 had a serum salicylate concentration equal to or greater than $2 \cdot 2 \mathrm{mmol} / 1$ (range $1 \cdot 4-3 \cdot 4 \mathrm{mmol} / \mathrm{l}$ ). Subjective hearing loss was reported more commonly in the subjects with salicylate concentrations above $1.4 \mathrm{mmol} / \mathrm{l}$. Upward salicylate dose adjustments were attempted in 24 of the subjects with serum salicylate concentrations less than $1.3 \mathrm{mmol} / \mathrm{l}$. Only nine were initially willing or able to tolerate a serum salicylate concentration above $1.4 \mathrm{mmol} / \mathrm{l}$, and four of these later discontinued the treatment because of ototoxicity; thus only five subjects were ultimately willing or able to continue salicylates in a dosage adequate to produce a therapeutic concentration. The salicylate dosage was decreased in 25 of the 26 patients with a salicylate concentration greater than $1.4 \mathrm{mmol} / \mathrm{l}$. Tinnitus improved or stopped in 17 and persisted in eight; of these 17, the salicylate concentration remained therapeutic in seven and became less than therapeutic in 10 . The one patient without a change in salicylate dosage had persistent tinnitus. Audiological evaluation was performed at least 10 days after discontinuing salicylates in most of the 56 patients. Despite the low incidence of previous ear disease reported, most audiograms were abnormal in both groups. Even though subjective hearing loss was more commonly reported in the group with a salicylate concentration greater than $1.4 \mathrm{mmol} / \mathrm{l}$, the largest percentage (83\%) of abnormal audiograms was in the group with a lower salicylate concentration. Sensorineural hearing loss was especially common in both groups.

Over a three year period 1601 serum salicylate concentrations were measured in 1124 patients, and $135(8.4 \%)$ from 94 patients (88 with rheumatoid arthritis, three with osteoarthritis, three with other disease) were greater than $1 \cdot 4$ $\mathrm{mmol} / \mathrm{l}$. When the results were known patients were asked whether tinnitus had been present when the test was done. Table 3 summarises the results. Patients with a previous history of tinnitus but not symptoms at the time the test was done were considered to have the symptom unrelated to the salicylate concentration. Only $28(30 \%)$ were symptomatic at the time the salicylate concentration was measured and 52 $(55 \%)$ reported no tinnitus at any time. Subjective hearing loss was difficult to correlate with the timing of the serum salicylate determination and all recent symptoms are reported in table 3 whether or not they were recognised as present at the time the blood was drawn. Table 4 summarises the audiometric responses in 54 of these 94 subjects. All patients had rheumatoid arthritis and audiological evaluations were performed at least 10 days after stopping salicylate treatment. Fifteen of 20 subjects reporting tinnitus $(75 \%)$ and 24 of 34 patients not reporting tinnitus (71\%) had abnormal audiograms.

\section{Discussion}

This study considers the specificity and sensitivity of tinnitus and (to a lesser degree) subjective hearing loss as reliable indicators of serum salicylate concentration. In our experience tinnitus was reported only slightly more often by patients taking regular salicylates than by healthy and rheumatic disease control groups not taking these drugs. Furthermore, most of our patients volunteering the symptom of tinnitus while taking salicylates had drug blood concentrations less than $1.3 \mathrm{mmol} / \mathrm{l}$ and most of these patients were unable to tolerate dose adjustments into the therapeutic range. Therefore not only does reported ototoxicity lack specificity for toxic serum salicylate concentrations it even lacks specificity for therapeutic concentrations. In fact, it has little specificity for salicylate consumption. Another problem, not specifically considered in this study, is the limitation imposed on salicylate use by these symptoms. It was apparent in most of the patients volunteering the symptom of tinnitus 
that it was caused, or at least aggravated, by salicylates. This implies that a significant number of patients ( $45 \%$ in a previous report ${ }^{6}$ ) will be unable to tolerate an adequate salicylate dose and will have to abandon that category of non-steroidal anti-inflammatory drug in favour of another. This is especially unfortunate in light of the accumulating evidence that the nonacetylated salicylates have significantly less gastric toxicity than do other non-steroidal antiinflammatory drugs. ${ }^{89}$

Over half of our patients with serum salicylate concentrations greater than $2 \cdot 2 \mathrm{mmol} / 1$ did not complain of recent tinnitus and the majority of those had noted no subjective hearing loss, even though $50 \%$ of those patients had concentrations above $2.5 \mathrm{mmol} / \mathrm{l}$. Therefore ototoxicity is too insensitive to be a reliable indicator of salicylate toxicity. Although this study did not consider the issue of ototoxicity in subjects with serious or life threatening salicylate concentrations, a useful clinical indicator of serum salicylate concentration should sound an alarm before serious complications occur, and ototoxicity does not seem to do that.

Most of our patients with apparent ototoxicity had abnormal audiograms and most had rheumatoid arthritis. Several possibilities exist to explain the high prevalence of abnormal audiograms in these subjects. Possibly, some patients might not have stopped taking their salicylate drugs, but the abnormal audiometrics seem to be more related to increasing age or the presence of rheumatoid arthritis than to serum salicylate concentration or the presence (or absence) of tinnitus. It has been reported that hearing loss (and abnormal audiometry) increases with aging, ${ }^{10}$ and rheumatoid arthritis itself has been associated with hearing loss. ${ }^{11}$ Our data (table 4) show that a normal audiometric response was found more often in younger rheumatoid patients with a shorter disease duration, whereas abnormal audiograms were more common and more severely abnormal in patients with a longer disease duration. In an attempt to answer some of the questions raised by this observation a continuing study is evaluating audiometric responses in a group of nonrheumatoid patients with and without salicylate treatment; audiograms are also being obtained prospectively and at regular intervals in younger patients with rheumatoid arthritis (under age 45) and in patients with disease of less than one year's duration.

One reason for the lack of sensitivity and specificity of tinnitus for salicylate ototoxicity is the increasing prevalence of tinnitus in the general population, and this prevalence is apparently independent of age. ${ }^{12} 13$ The National Center for Health Statistics has reported that about $32 \%$ of all adults in the United States acknowledge having tinnitus ${ }^{12}$; and the American Tinnitus Association suggests that while almost everyone experiences tinnitus, about nine million American adults have severe unremitting symptoms. ${ }^{13}$ The increased prevalence of the symptom has been related to our current noise polluted environment, especially the work place, ${ }^{14}$ and may explain the lack of correlation between audiometric responses and tinnitus.

Tinnitus is a common and non-specific symptom, but it (and subjective hearing loss) is also clearly caused or aggravated by salicylates. In that case patients often become symptomatic at subtherapeutic serum salicylate concentrations, necessitating a change to another category of non-steroidal anti-inflammatory drug. As previously suggested by us and by others, 2615 symptomatic ototoxicity is too non-specific and too insensitive to be a clinically useful indicator of serum salicylate concentration.

1 Kimberly R P, Plotz P H. Salicylates including aspirin and salfasalazine. In: Kelley W N, Harris E D, Jr, Ruddy S, Sledge C B, eds. Textbook of rheumatology. 3rd ed. Philadelphia: Saunders, 1989: 739-64.

2 Paulus H E, Furst D E. Aspirin and other nonsteroidal antiinflammatory drugs. In: McCarty D J, ed. Arthritis and allied conditions. 1lth ed. Philadelphia: Lea and Febiger, 1989: 507-43.

3 Mongan E, Kelly P, Nies K, Porter W W, Paulus H E. Tinnitus as an indicator of therapeutic serum salicylate levels. FAMA 1973; 226: 142-5.

4 Paulus H E, Siegal M, Mongan E, Okun R, Calabro J J. Variations of serum concentrations and half-life of salicylate in patients with rheumatoid arthritis. Arthritis Rheum 1971; 14: $527-32$.

5 Furst D E, Blocka K, Cassell S, et al. A strategy for reaching therapeutic salicylate levels in patients with rheumatoid arthritis using standardized dosing regimens. $\mathcal{J}$ Rheumatol 1987; 14: 342-7.

6 Halla J T, Hardin J G. Salicylate ototoxicity in patients with rheumatoid arthritis: a controlled study. Ann Rheum Dis 1988; 47: 134-7.

7 Keller W J. A rapid method for the determination of salicylates in serum or plasma. Am $\mathcal{F}$ Clin Pathol 1947; 17 415-7.

8 Lanza F, Rack M F, Doucette M, et al. An endoscopic comparison of the gastroduodenal injury seen with salsalate and naproxen. I Rheumatol 1989; 16: 1570-4.

9 Roth S, Bennett R, Caldron P, et al. Reduced risk of NSAID gastropathy (GI mucosal toxicity) with nonacetylated salicylate (salsalate): an endoscopic study. Semin Arthriti Rherum 1990; 19: 11-19.

10 Alpiner J G. Rehabilitative audiology. An overview. In: Alpiner J G, McCarthy P F, eds. Rehabilitative audiology in children and adults. 2nd ed Baltimore: Williams and Wilkins, 1987: 3-17.

11 Heyworth T, Liyange S P. A pilot survey of hearing loss in patients with rheumatoid arthritis. Scand $\mathcal{J}$ Rheumatol patients with
1972; $1: 81-3$.

12 Sataloff $R$ T. Tinnitus: progress and problems in research. Hearing Instruments 1989; 40: 22

13 Vernon J. Tinnitus 1989. Current knowledge and treatment therapy. The Hearing fournal 1989; 42: 7-11.

14 Melnick $\mathbb{W}$. Compensation for hearing loss from occupational noise. Seminars in Hearing 1988; 9: 339-49.

15 Champion G D, Day R O, Graham G G, Paull P D Salicylates in rheumatoid arthritis. Clin Rheum Dis 1975; 1: 245-65. 